\title{
Dynamic Response of Femoral Cartilage in Knees With Unicompartmental Osteoarthritis
}

\author{
A. Vidal-Lesso* ${ }^{* 1}$ E. Ledesma-Orozco ${ }^{2}$, R. Lesso-Arroyo ${ }^{3}$, R. Rodríguez-Castro ${ }^{4}$ \\ ${ }^{1,2}$ Department of Mechanical Engineering. Universidad de Guanajuato, \\ Campus Irapuato-Salamanca. Salamanca-Valle de Santiago Highway, \\ $\mathrm{Km}$ 3.5+1.8. Salamanca, Guanajuato, Mexico. \\ ${ }_{3,4}$ Department of Mechatronic Engineering. Instituto Tecnológico de Celaya. \\ Tecnologico Avenue and Antonio Garcia Cubas Street, 38010, Celaya, Gto, Mexico. \\ *avidal@itc.mx
}

\begin{abstract}
The objective of the present work was to determine the dynamic indentation response, stiffness and relaxation curves for the shear and the bulk modulus of femoral knee cartilage with no visual damage in cases under unicompartmental osteoarthritis.
\end{abstract}

A cyclic displacement of $0.5 \mathrm{~mm}$ in axial direction was applied with a $3 \mathrm{~mm}$ plane-ended cylindrical indenter at specific points in the femoral knee cartilage specimens of seven patients with unicompartmental osteoarthritis (UOA). The indentation force over time was recorded and next the maximum stiffness in all cycles was obtained and compared. Also, the relaxation curves for the shear and the bulk modulus of cartilage were obtained in this work.

A decrease in the maximum indentation force was observed comparing between indentation cycles; it was of $6.75 \pm$ $0.71 \%$ from cycle 1 to cycle 2 and $4.70 \pm 0.31 \%$ for cycle 2 to cycle 3 . Stiffness values changed with a mean of $3.35 \pm$ $0.39 \%$ from cycle 1 to cycle 2 and $1.40 \pm 0.71 \%$ from cycle 2 to cycle 3 . Moreover, relaxation curves for the shear modulus and the bulk modulus showed the nonlinear behavior of articular cartilage with UOA.

Our results showed that cartilage specimens with no visual damage in UOA preserve a nonlinear viscoelastic behavior and its stiffness increases through the loading cycles. Our work provides experimental values for generating a more realistic cartilage behavior than those currently used in computer cartilage models for the study of UOA.

Keywords: Osteoarthritis, cartilage, dynamic response, biomechanics.

\section{RESUMEN}

El objetivo de este trabajo fue determinar la respuesta dinámica de indentación, la rigidez y las curvas de relajación para módulo cortante y volumétrico de cartílago femoral de rodilla con daño no visual en casos con osteoartritis unicompartimental.

Se aplicó un desplazamiento cíclico de $0.5 \mathrm{~mm}$ en dirección axial con un indentador cilíndrico plano de $3 \mathrm{~mm}$ en puntos específicos de los especímenes de cartílago femoral de rodilla de siete pacientes con osteoartritis unicompartimental (OAU). La fuerza de indentación a través del tiempo fue registrada, obteniéndose y comparándose la máxima rigidez en todos los ciclos. Además, en este trabajo se obtuvieron las curvas de relajación para el módulo cortante y volumétrico de cartílago.

Se observó una disminución en la fuerza de indentación máxima comparando entre los ciclos de indentación; ésta fue $6.75 \pm 0.71 \%$ del ciclo 1 al 2 , y $4.70 \pm 0.31 \%$ del ciclo 2 al 3 . Los valores de rigidez cambiaron $3.35 \pm 0.39 \%$ entre el ciclo 1 y 2 , y $1.40 \pm 0.71 \%$ entre el ciclo 2 y 3 . Además, las curvas de relajación para el módulo cortante y volumétrico mostraron el comportamiento no lineal del cartílago articular con OAU.

Los resultados mostraron que los especímenes de cartílago con daño no visual en OAU preservan un comportamiento viscoelástico no lineal y su rigidez se incrementa a través de los ciclos de carga. Este trabajo provee valores experimentales para generar un comportamiento de cartílago más real que el utilizado actualmente en modelos computacionales de cartílago para el estudio de OAU. 


\section{Introduction}

The articular cartilage has a finite deformation due to physiological load [1] and works as a mechanical damping surface in the synovial joints [2, 3]. These kinds of joints are exposed to degenerative diseases like osteoarthritis, where the articular cartilage wears out and causes musculoskeletal pain and disability. In these cases, osteoarthritis of the entire knee is distinguished from osteoarthritis of one compartment (unicompartmental osteoarthritis), where one compartment is damaged and the other one is considered as healthy. However, the visual and histological appearance of tissue is not a good indicator of performance in a synovial joint and it requires a biomechanical evaluation $[4,5]$.

Several works [6-11] have reported the analysis of the cartilage biomechanical behavior, they include different studies such as the dynamic behavior of biphasic cartilage model [6], the effect of mechanical dynamic force in the cartilage metabolism [7], the dynamic elastic modulus [8], the dynamic deformation of patellar cartilage [9], the effect of dynamic compression loads in proteins and molecules to repair cartilage [10], and the mechanical behavior of cartilage under tension fatigue loading [11]. These studies have been realized applying cyclic loading by unconfined compression in human, bovine and porcine healthy cartilage.

However, some works have used static load to determine the mechanical properties [2, 12-16] and thickness [2, 17-19] of healthy cartilage and tibial cartilage with osteoarthritis [4]. At present, there are no reported studies about the dynamic mechanical behavior of femoral cartilage with any visual damage in unicompartmental knee osteoarthritis. These studies are necessary in cases of surgery for unicompartmental knee replacement due to the cartilage with no visual damage is preserved and it could have an undesirable biomechanical response. It could impact the mechanical performance of the knee, unicompartmental prosthesis and life quality of the person. Therefore, we present a study of the dynamic response of femoral knee cartilage in specimens with unicompartmental osteoarthritis. Our work provides experimental values of indentation force and stiffness through cycles and relaxation curves for the shear modulus and the bulk modulus over time. These experimental values can be used for generating a more real cartilage behavior than those currently used in computer cartilage models for the study of UOA [2].

\section{Materials and methods}

\subsection{Specimens}

The specimens were removed during surgery for total knee replacement so it was possible to obtain cartilage with subchondral bone of femoral compartment (see Figure 1). Seven femoral knee specimens were obtained from female patients diagnosed with unicompartmental osteoarthritis, which came from a non-cadaveric population with ages ranging from 59 to 73 years old. The knee specimens have been donated by patients under administrative control of the Mexican Social Security Institute (IMSS) for scientific and medical research.

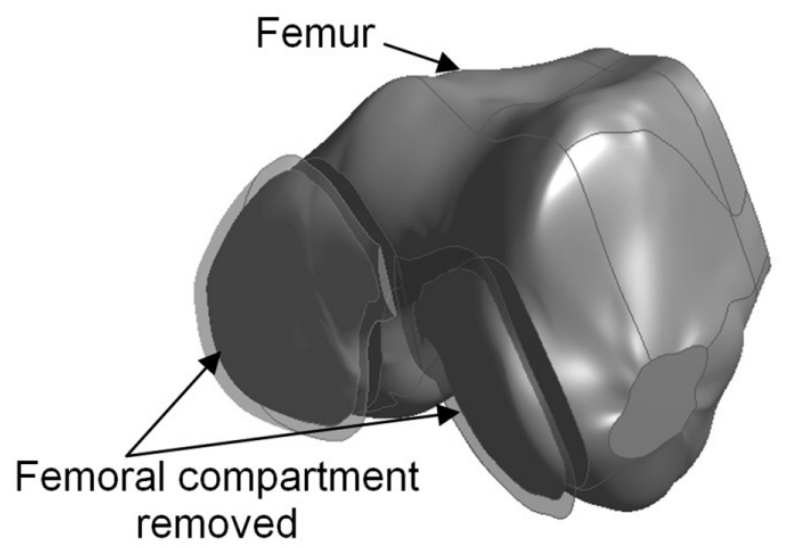

Figure 1. Schematic specimens removed with cartilage and subchondral bone during surgery for total knee replacement.

\subsection{Groups}

Relaxation and cyclic indentation tests on cartilage of lateral femoral compartments were performed using an impermeable plane-ended cylindrical indenter. Five points on the surface of each femoral compartment were selected for cartilage dynamic testing. Each point was identified and associated with a group (Figure 2), named and described as follows: 
- AP: anterior point.

- CP: central point.

- LP: lateral point.

- MP: medial point.

- PP: posterior point.

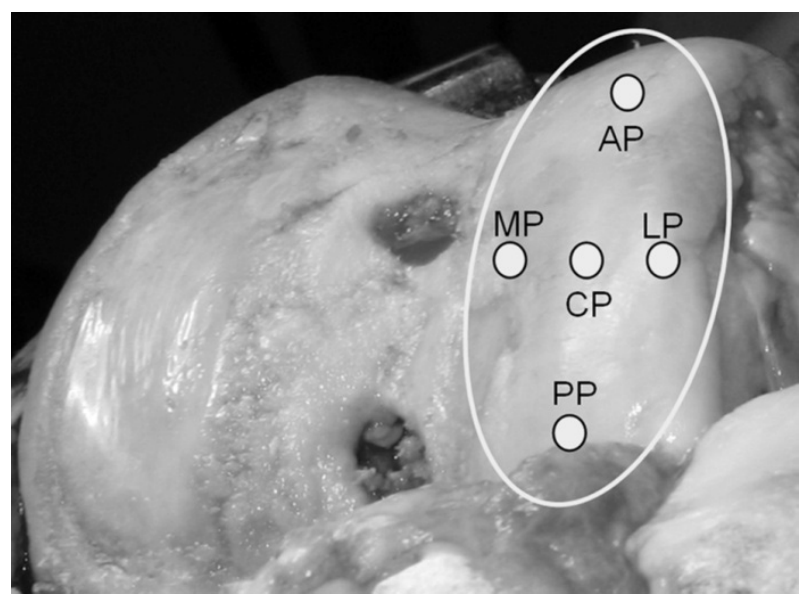

Figure 2. Test points in femoral knee compartment.

\subsection{Indentation test}

A common technique for measuring the compressive properties of cartilage is through indentation $[20,21]$. For this procedure, a probe of specified geometry (e.g., cylindrical, spherical or pyramidal) is indented into a material. Elastic properties of different materials can be obtained through this technique, which has also been developed to characterize the time-dependent properties of viscoelastic materials [22].

Our test of cartilage indentation has been performed using similar testing protocols of several works [6, 21, 23] and the mathematical analysis for indentation tests of articular cartilage reported by Hayes et al. [24]. Therefore, we determined instantaneous stiffness values rather than those in steady state because (during the immediate response of the cartilage after application of load) it behaves as an incompressible elastic material of a single phase. Since the fluid in the cartilage is unable to flow due to the short time of load application [21, 23, 25]. In order to achieve this, a rapid rate of load application is required to reduce or eliminate the relaxation effect.
Cartilage specimens with subchondral bone were tested without doing any additional cutting, which preserves the specimen free of any induced mechanical effects on the test site. Thus, a cyclic displacement of $0.5 \mathrm{~mm}$ was applied to the cartilage in axial direction with a $3 \mathrm{~mm}$ diameter rigid indenter attached to a $500 \mathrm{~N}$ load cell of a materials testing machine (CHATILLON® TCD200). This displacement corresponds to a real physiological displacement of $25-30 \%$ [1]. The indenter diameter should be at least one third of the specimen diameter size (plugs of cartilage with subchondral bone) to avoid the stiffness effect of the subchondral bone on cartilage measurements, which has been suggested in previous analysis [4, 21]. In this work, we did not take plugs of cartilage to avoid any induced mechanical effects on the test site; we tested the complete femoral compartment, which was done in previous studies on tibia [12]. Thus, the small size of the indenter diameter in this work is less than one third of the indentation area on the complete cartilage specimens.

The physiological normal state of cartilage hydration was considered in this work. The cartilage specimens were hydrated regularly with saline solution to prevent dehydration of the indentation surface and cells during the whole test. Each specimen was fixed in a platform where it could be carefully adjusted in any position so the cartilage surface was just in contact and perpendicular to the longitudinal axis of the indenter (see Figure 3). In order to avoid the influence between two indentation test points in the specimen, we waited for five to eight minutes for total recovery of the indented surface before starting with the next point. About five minutes for total recovery of the indented surface was observed and reported by Thambyah A. et al. [12] in cartilage of tibia. During this time, the specimen was hydrated to prevent dehydration of cells. The displacement cycles are applied with a strain rate of $0.21 \mathrm{~mm} / \mathrm{s}$ at each test point. This strain rate corresponds to a loading frequency of $0.1 \mathrm{~Hz}$. In other studies, the need to analyze the mechanical response of bovine articular cartilage at physiological stress levels [26] and to study the enzymatic degradation under dynamic unconfined compression loading [27] have been reported. In addition, some works have reported that 
frequencies ranging from 0.01 to $2 \mathrm{~Hz}$ kept the majority of interstitial fluid inside the cartilage, which reproduces the phenomenon created by the real physiological frequencies in a human body [28-32]. Thus, the value used in the present work reproduce physiological cyclic loading, as it was done in previous studies.

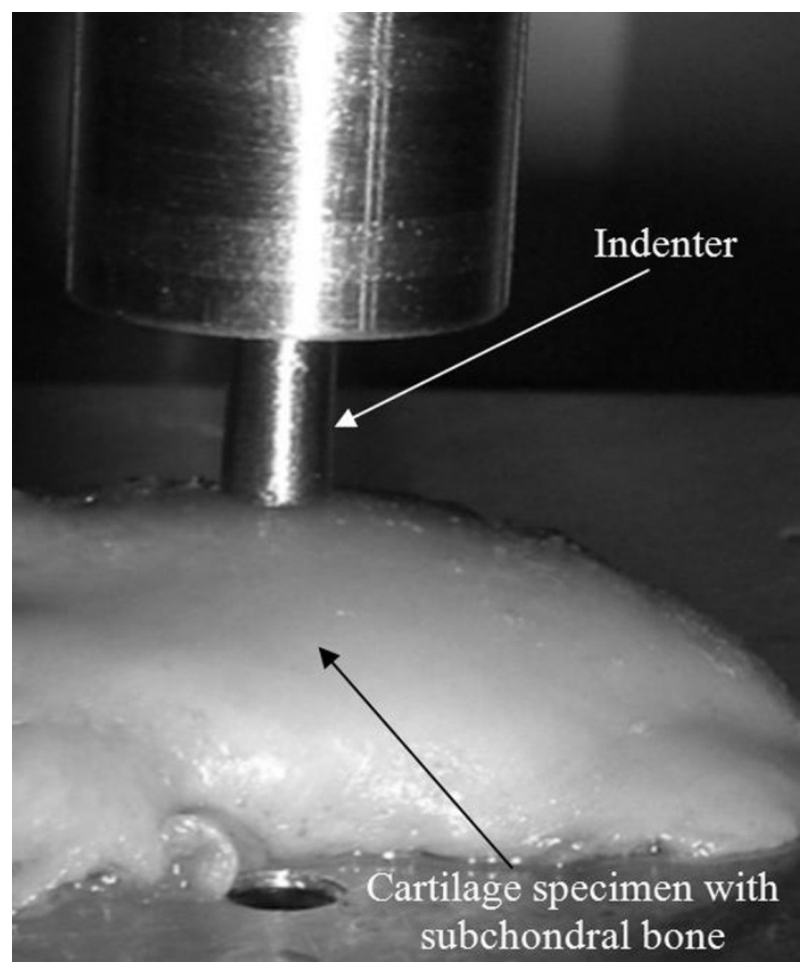

Figure 3. Cartilage specimen of femoral compartment for indentation test.

Furthermore, test runs were performed at the same points for all specimens and repeatability of cartilage response was observed. Force, time and displacement parameters were recorded during each test run.

\subsection{Relaxation test}

Cartilage response to relaxation over time was obtained using the same $3 \mathrm{~mm}$ plane-ended cylindrical indenter as it was done in the indentation test. Specimens were fixed in a platform where they can be carefully adjusted so the cartilage surface is just in contact and perpendicular to the longitudinal axis of the indenter. A displacement of $1 \mathrm{~mm}$ in the axial direction was applied to each test point of the cartilage specimen mentioned above (see Figure 2) and force and relaxation time were recorded during fifty seconds followed by cartilage unloading. The specimens were hydrated regularly with saline solution to prevent dehydration of the indentation surface and cells during testing time. Also, this reproduces the physiological normal state of cartilage hydration.

\subsection{Determining stiffness and relaxation modulus}

Using the force values, time and displacement recorded in the indentation (see Figure 4) and the relaxation test, the following values were obtained:

- Percentage reduction of indentation force between cycles (\%)

- Maximum mean stiffness (N/mm)

- Relaxation of the shear modulus (MPa)

- Relaxation of the bulk modulus (MPa)

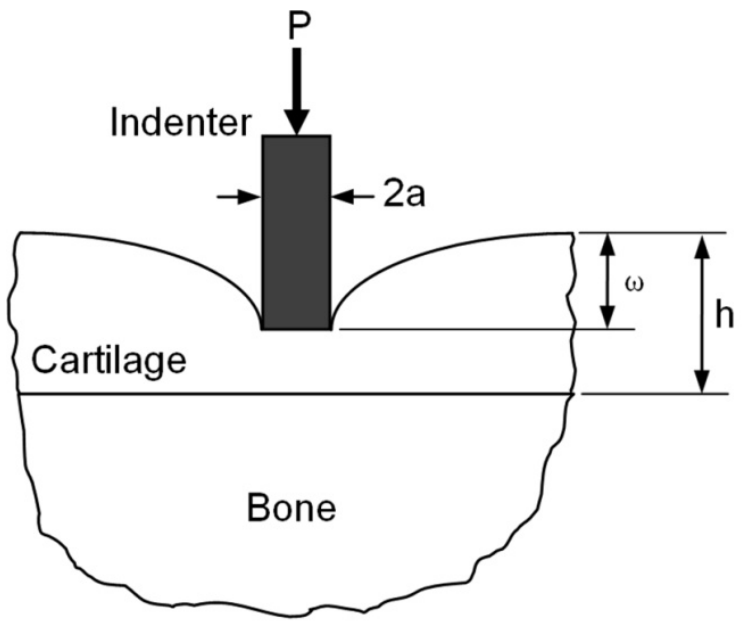

Figure 4. Schematic indentation test in cartilage with subchondral bone.

The resistance of an elastic body to deformation by an applied force is known as stiffness. Stiffness values were obtained normalizing the force values recorded over time in the cyclic indentation test to the corresponding depth of indenter penetration. This procedure to compute the stiffness was followed in previous works reported by Thambyah A. et al. [12] and Lyyra T. et al. [23]. Also, the relaxation of the shear modulus was obtained linking the mathematical model for the instantaneous elastic modulus reported by Hayes et al. [24] with the well- 
known isotropic relation between the shear modulus and the elastic modulus. Thus, the relaxation of the shear modulus can be determined by

$$
\mathrm{G}=\frac{P(1-\mathrm{v})}{4 a \omega K}
$$

where $\mathrm{G}=$ instantaneous shear modulus

$\mathrm{P}=$ indentation force

$\mathrm{v}=$ Poisson ratio

$a=$ radius of the indenter

$\omega=$ depth of indenter penetration

$\mathrm{K}=$ scaling factor of Hayes et al. [24]

The Poisson ratio is approximately 0.45 for the cartilage considered as an incompressible material $[21,23,25]$ and when the load is applied for a short period of time [33]. In addition, relaxation of the bulk modulus for the cartilage specimens can be estimated as

$$
K=\frac{2 G(1+v)}{3(1-2 v)}
$$

where $\mathrm{K}=$ instantaneous bulk modulus

$\mathrm{G}=$ instantaneous shear modulus $\mathrm{v}=$ Poisson ratio

\section{Results}

Figure 5 shows the general behavior of the indentation force as function of time for all cartilage specimens, which decreases through cycles. In addition, the viscoelastic effect has been observed between the loading and unloading curves, where relaxation of the indentation force is presented. This effect in all cycles is related to the change of movement direction of the indenter, which last approximately 1.5 seconds where the indentation depth is $0.5 \mathrm{~mm}$. Also, a nonlinear behavior is observed at the beginning and at the end of each cycle for all cartilage specimens.

The application of the second cycle of displacement (Figure 6) shows that the indentation force decreases for the nonlinear loading curve as well as in the unloading curve. Also, the maximum

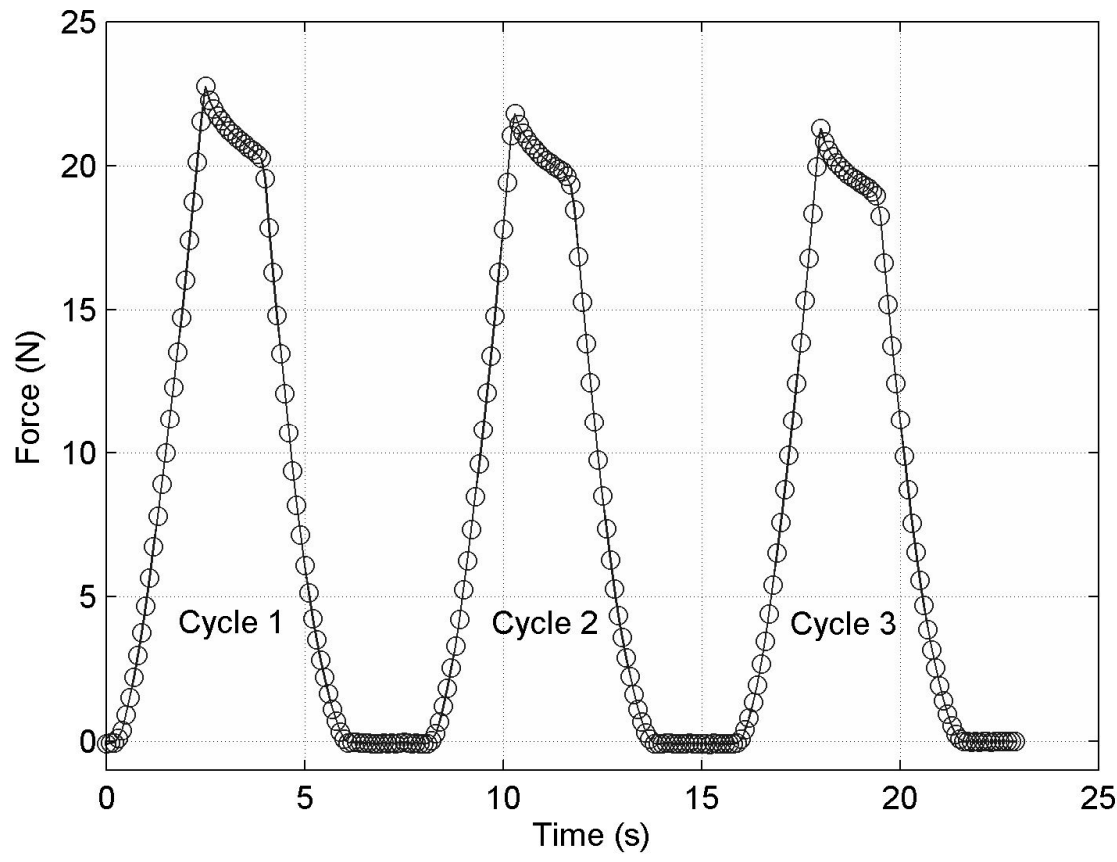

Figure 5. General behavior of the indentation force as function of time for specimens from femoral articular cartilage under unicompartmental osteoarthritis. Three consecutive cycles applied to the specimens are shown. 


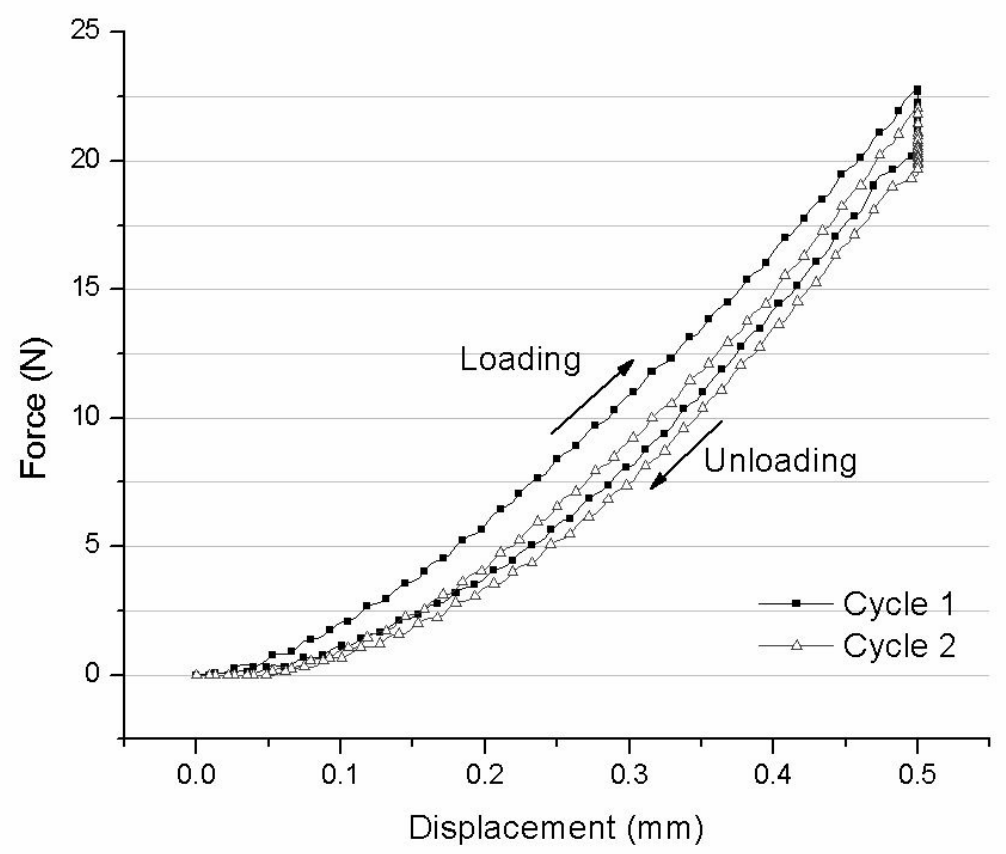

Figure 6. Indentation force behavior versus displacement for cycles 1-2 in one specimen of articular cartilage under unicompartmental osteoarthritis.

indentation force to achieve the final displacement of $0.5 \mathrm{~mm}$ in cycle 2 decreased in relation with the maximum indentation force recorded in cycle 1 . This behavior was presented in cycle 2 for all cartilage specimens tested in the present work.

The same behavior of the indentation force is observed for the third cycle of displacement (see Figure 7) since the maximum indentation force decreases in the loading and unloading curves between consecutives cycles. For this comparison, the percentage decrease of the maximum indentation force is less to that obtained with the previous cycles 1-2.

In order to analyze the decrease of the maximum indentation force between cycles 1-2 and cycles 23 , the percentage decrease is computed for all cases. This value is observed for the different test points, as shown in Figures 8 and 9.

The MP point presented the maximum force decrease through cycles 1-2 (see Figure 8) while the $\mathrm{CP}, \mathrm{AP}$ and LP points presented similar mean values of force decrease.

For the second and third cycles, the MP point presented th e maximum force decrease as it was also shown between the first and second cycles; however, in this case, the CP, AP, LP and PP points presented similar mean values of force decrease (see Figure 9).

Percentage values of the tested points have a general mean force decrease of $6.75 \pm 0.71 \%$ between cycle one and two while it is $4.70 \pm 0.31 \%$ between cycle two and three.

Table 1 shows the mean values and standard deviations (SD) of stiffness magnitudes obtained in the different test points of the cartilage in the lateral femoral compartment in each cycle. Based on these values, the cartilage stiffness increases between one and two cycles; however, it has a minor change between two and three cycles. The maximum stiffness occurs at point MP while the LP point has the minimum stiffness value in all cycles. 


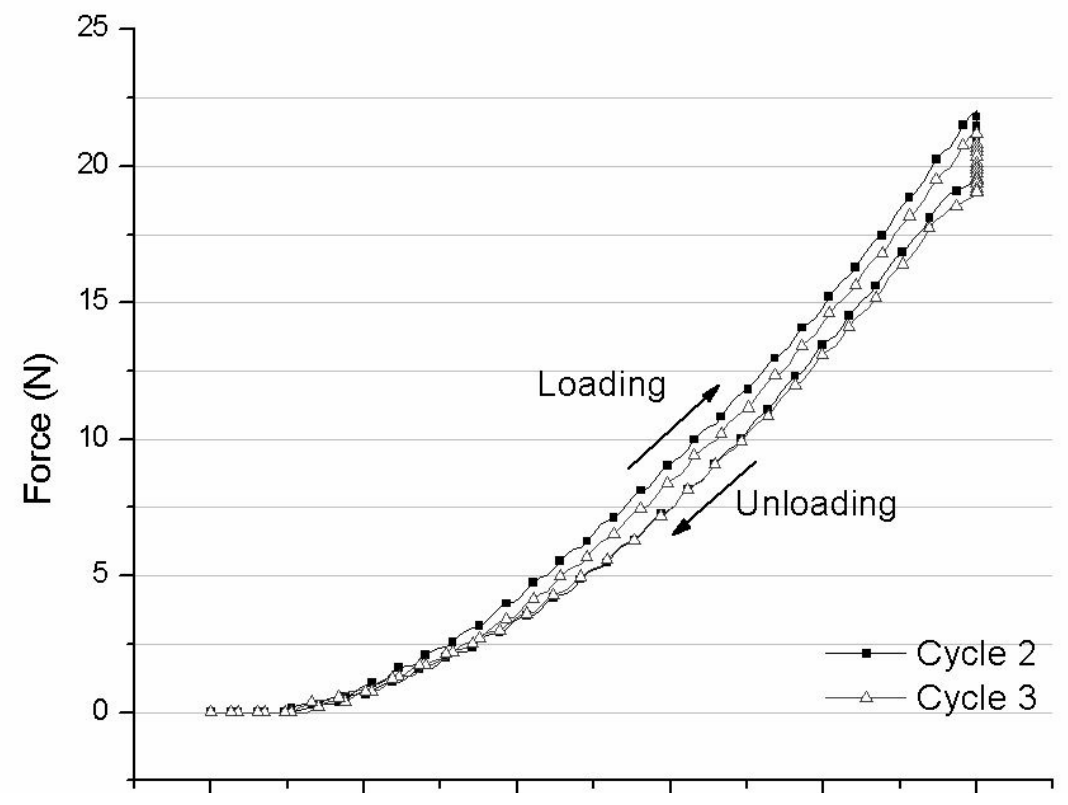

Figure 7. Indentation force behavior versus displacement of the indenter for cycles 2-3 in one specimen of articular cartilage under unicompartmental osteoarthritis.

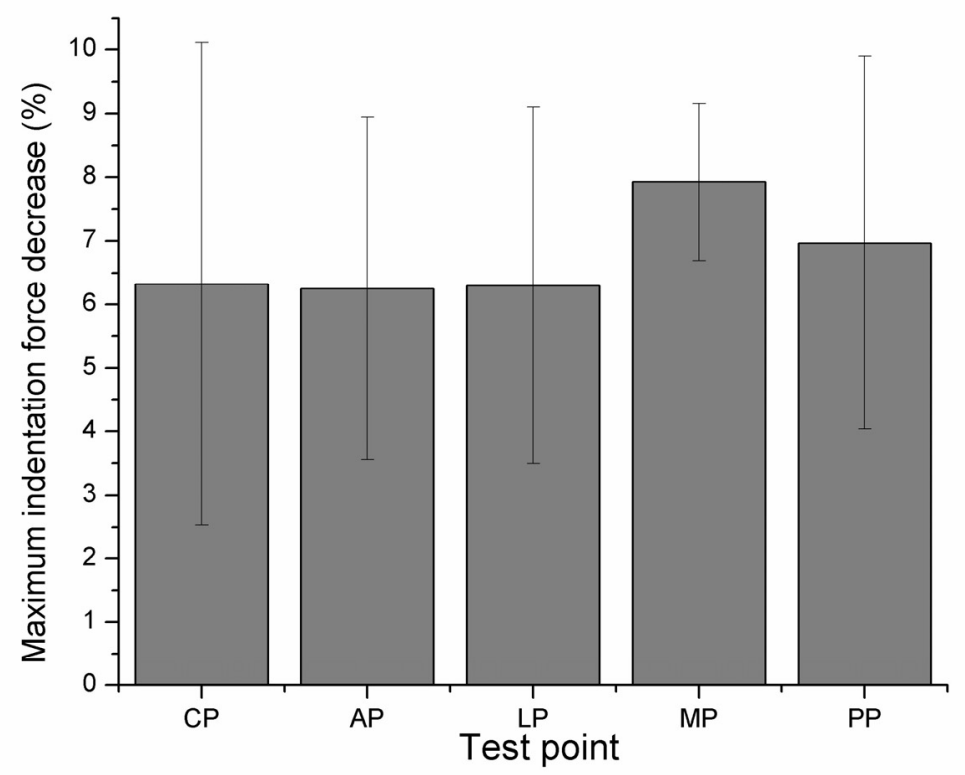

Figure 8. Percentage decrease in the maximum indentation force between cycles 1-2 for all test point in the femoral specimens of articular cartilage under unicompartmental osteoarthritis. 


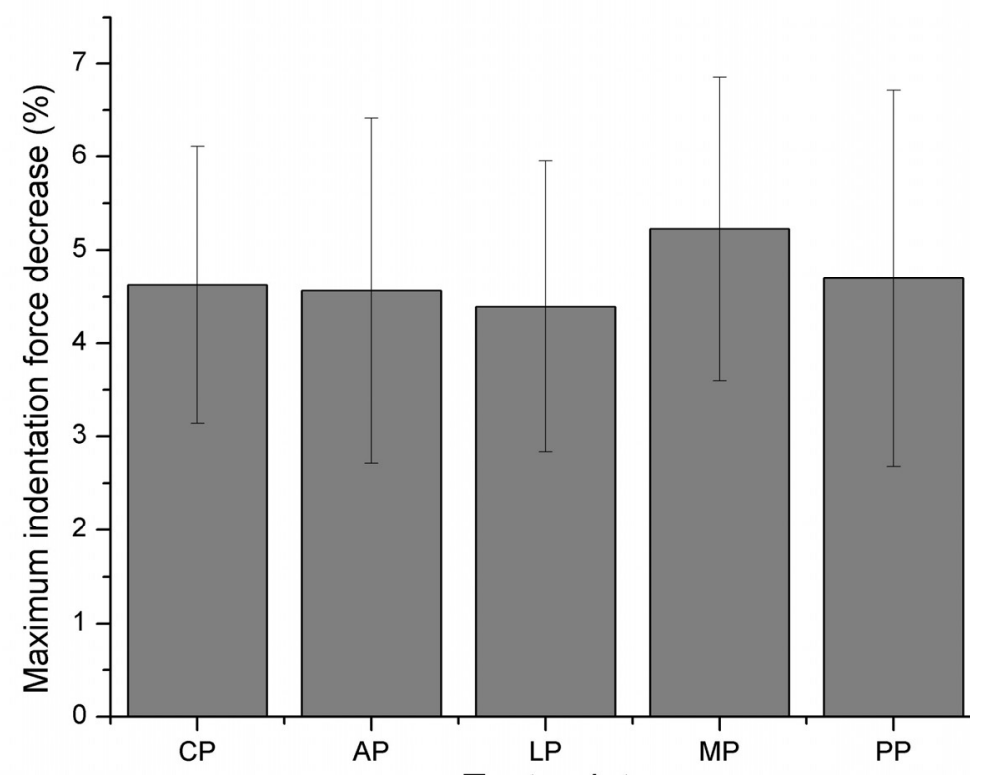

Figure 9. Percentage decrease in the maximum indentation force between cycles 2-3 for all test point in the femoral specimens of articular cartilage under unicompartmental osteoarthritis.

\begin{tabular}{ccccc}
\hline Test point & $(\mathrm{N}=7)$ & Cycle 1 & Cycle 2 & Cycle 3 \\
\hline \multirow{2}{*}{ CP } & Mean & 58.32 & 59.97 & 58.51 \\
& SD & 35.16 & 32.67 & 33.01 \\
AP & Mean & 47.27 & 48.99 & 49.91 \\
& SD & 23.45 & 26.91 & 28.81 \\
LP & Mean & 43.16 & 44.46 & 44.04 \\
& SD & 21.6 & 21.62 & 22.07 \\
MP & Mean & 80.37 & 83.34 & 82.44 \\
& SD & 34.25 & 38.32 & 39.46 \\
PP & Mean & 50.01 & 51.79 & 52.16 \\
& SD & 21.28 & 24.06 & 23.32 \\
\hline
\end{tabular}

Table 1. Results of indentation cyclic testing for cartilage in unicompartmental osteoarthritis cases (Stiffness, N/mm). 
Relaxation curves at each test point were obtained for all compartments and mean values are shown in Figure 10. The relaxation test showed a viscoelastic nonlinear behavior for the articular cartilage of the knee (see Figure 10).

\section{Discussion}

The indentation force decreased in the cartilage specimens through the increase of the cycles. It can be related to the viscoelastic and biphasic behavior of cartilage which causes that the recovery is not instantaneous and the fluid flow in the cartilage is present in the indentation region $[34,35]$. Thus, between consecutives cycles there is no time for total recovery and there is an initial deformation after the first cycle. The fluid flow has an important role in the mechanical behavior of the tissue. For instance, mechanical compression of cartilage causes a rapid pressurization of the fluid in the tissue, which in turn supports the load. This pressurization allows the longevity of cartilage under repeated compression since loading is supported by fluid instead of a solid-solid interaction [36, 37]. Time-dependent changes occur in the fluid movement due to the fact that the fluid redistributes within the tissue, which contributes to the viscoelastic properties of the tissue. Due to the fluid pressure decrease over time, the solid fraction of the matrix suffers a higher load, giving rise to creep and stress relaxation behaviors [38]. Thus, the increase of cartilage stiffness (see Table 1) can be related with the loss of fluid pressure and fluid movement, which causes a higher load in the solid fraction of the matrix in the second and third cycle.

In addition, the effect of the fluid flow over the cartilage behavior is observed in the curves of the indentation force versus displacement (see Figs. 6 and 7 ) since the differences between the first and second cycle are notorious with mean decrease of $6.75 \pm 0.71 \%$ for the maximum indentation force; however, Figure 7 shows a decrease in the difference between the curves for the second and third cycle with a mean of $4.70 \pm 0.31 \%$ for maximum indentation force. It can be attributed to

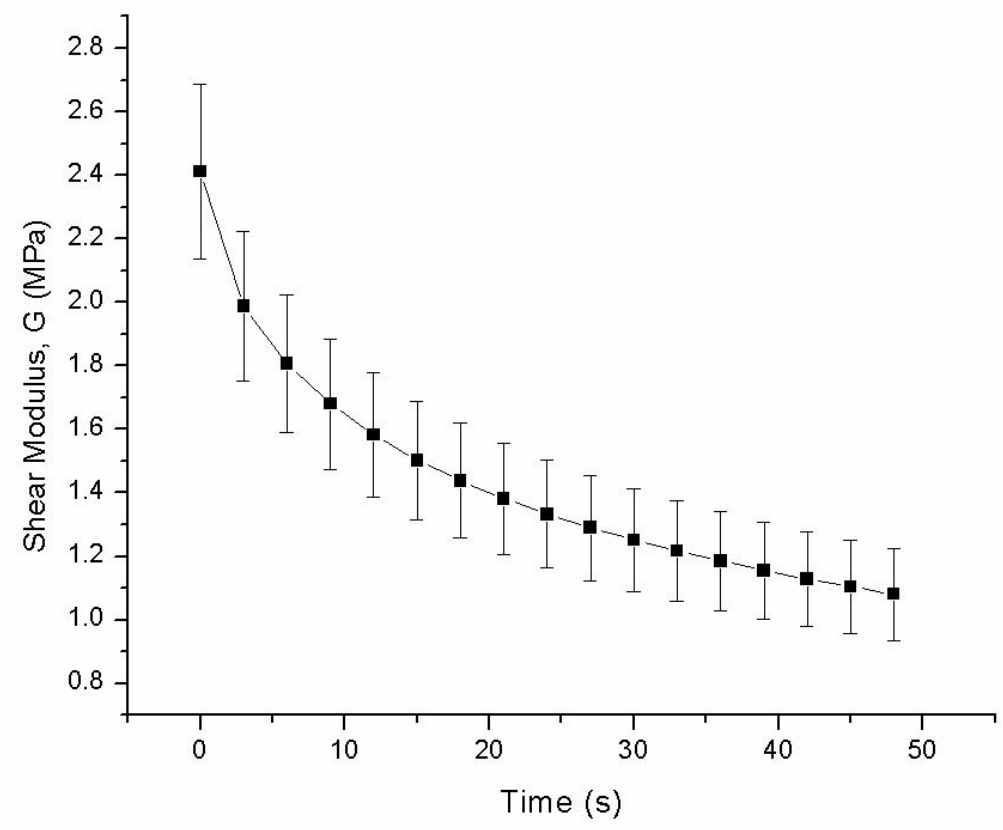

Figure 10. Relaxation shear modulus versus time for femoral knee cartilage with no visual damage in unicompartmental osteoarthritis cases. 


\section{Dynamic Response of Femoral Cartilage in Knees With Unicompartmental Osteoarthritis A. Vidal-Lesso et al., 173-187}

the load supported by the solid fraction of the matrix. For this case, the fluid flow between the second and third cycle is less than the fluid flow between the first and second cycle.

Moreover, the percentage decrease in force is preserved between the different specimens and analyzed points (see Figures 8 and 9). This implies a common viscoelastic biomechanical behavior of cartilage specimens with no visual damage in knees with unicompartmental osteoarthritis.

In addition, we obtained larger values of stiffness for points AP, CP, PP and MP, which correspond to the displacement line of the kinematic axis of flexion [39] and areas of cartilage-cartilage contact [37] and load in the knee [40]. Nevertheless, the LP point corresponds to the lowest load in the knee. Also, the cartilage stiffness values (see Table 1) are larger in magnitude to those found for healthy cartilage in previous studies [12, 23].
Moreover, the relaxation test showed the nonlinear viscoelastic cartilage behavior over time. The maximum mean value obtained for the shear modulus in this test for a Mankin score 3 for all specimens was $2.42 \pm 0.27 \mathrm{MPa}$. This value is between the range of 1.6 to 6.4 $\mathrm{MPa}$ reported in human femoral compartments with Mankin score from 1 to 7 [41-42]. Also, mean values of the shear modulus in human cartilage of $3.34 \mathrm{MPa}$ in the lateral compartment and $3.67 \mathrm{MPa}$ in the medial compartment for Mankin scores of 4 and 4.5, respectively, have been reported [43]. Finally, the relaxation bulk modulus of the cartilage specimens (see Figure 11) has a nonlinear behavior similar to that obtained in the relaxation curve of the shear modulus. This is attributed to the consideration of the Hayes' isotropic model [24], which produces a linear relationship between the shear modulus and the bulk modulus.

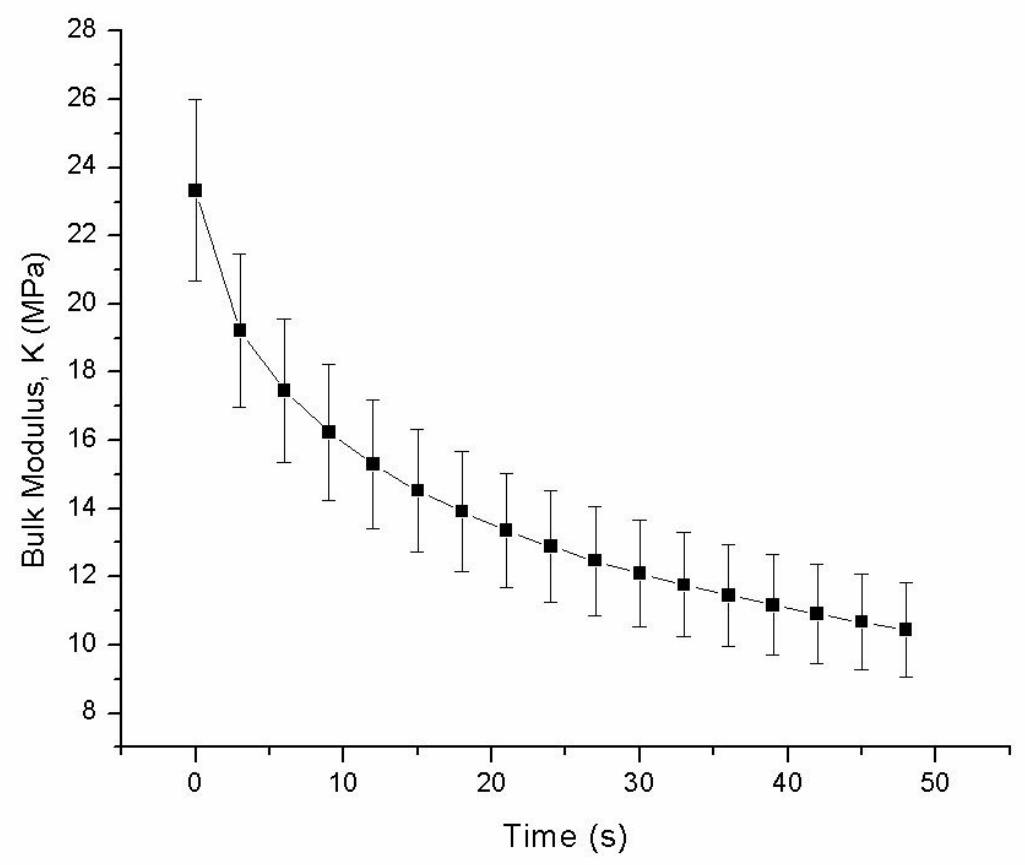

Figure 11. Relaxation bulk modulus versus time for femoral knee cartilage with no visual damage in unicompartmental osteoarthritis cases. 


\section{Conclusion}

We showed that femoral cartilage with no visual damage in unicompartmental osteoarthritis cases preserves a dynamic nonlinear viscoelastic behavior. The cartilage specimens presented relaxation and delay in recovery. A common percentage decrease in the indentation force between cartilage specimens was observed. Also, the stiffness values of cartilage specimens through cycles showed that the cartilage stiffness increases between the first and second cycle; however, it has a minor change between the second and third cycle.

Our work provides experimental values of indentation force and stiffness through cycles and relaxation curves for the shear modulus and the bulk modulus over time. These experimental values can be used for validation of numerical material models to reproduce a more real cartilage behavior than those currently used in computer cartilage models for the study of UOA and unicompartmental knee arthroplasty. Also, these values allow us to know the stiffness requirements for the design of unicompartmental prosthesis in cases of UOA.

\section{References}

[1] Herberhold C., Faber S., Stammberger T., Steinlechner M., Putz R., Englmeier K. H., Reiser M., Eckstein F. In situ measurement of articular cartilage deformation in intact femoropatellar joints under static loading. Journal of Biomechanics, Vol. 32, No. 12, December, 1999, pp. 1287-1295.

[2] Hopkins A. R., New Andrew M., Rodriguez-y-Baena F., Taylor M. Finite element analysis of unicompartmental knee arthroplasty. Medical Engineering \& Physics, Vol. 32, No. 1, January, 2010, pp. 14-21.

[3] Huang C., Soltz M. A., Kopacz M., Mow V. C., Ateshian G. A. Experimental verification of the roles of intrinsic matrix viscoelasticity and tension-compression nonlinearity in the biphasic response of cartilage. Journal of Biomechanical Engineering, Vol. 125, No. 1, February, 2003, pp. 84-93.

[4] Obeid E. M. H., Adams M. A., Newman J. H., Mechanical properties of articular cartilage in knees with unicompartmental osteoarthritis, Journal of Bone and Joint Surgery, Vol. 76, No. 2, 1994, pp. 315-319.

[5] Armstrong C. G., Mow V. C., Variations in the intrinsic mechanical properties of human articular cartilage with age, degeneration, and water content, Journal of Bone and Joint Surgery, Vol. 64, No. 1, January, 1982, pp. 88-94.

[6] Jun-Kyo S., Zhengfang L., Savio L-Y. W., Dynamic behavior of a biphasic cartilage model under cyclic compressive loading, Journal of Biomechanics, Vol. 28, No. 4, April, 1995, pp. 357-364.

[7] Suh J-K., Dynamic unconfined compression of articular cartilage under a cyclic compressive load, Biorheology, Vol. 33, No. 4, July/October, 1996, pp. 289-304.

[8] Stolz M., Raiteri R., Daniels A. U., VanLandingham M. R., Baschong W., Aebi U., dynamic elastic modulus of porcine articular cartilage determined at two different levels of tissue organization by indentation-type atomic force microscopy, Biophysical Journal, Vol. 86, No. 5, May, 2004, pp. 3269-3283.

[9] Eckstein F., Lemberger B., Stammberger T., Englmeier K. H., Reiser M., Patellar cartilage deformation in vivo after static versus dynamic loading, Journal of Biomechanics, Vol. 33, No. 7, July, 2000, pp. 819-825.

[10] Davisson T., Kunig S., Chen A., Sah R., Ratcliffe A., Static and dynamic compression modulate matrix metabolism in tissue engineered cartilage, Journal of Orthopaedic Research, Vol. 20 , No. 4, July, 2002, pp. 842-848. 
[11] Bellucci G., Seedhom B. B., Mechanical behaviour of articular cartilage under tensile cyclic load, Rheumatology, Vol. 40, No. 12, December, 2001, pp. 1337-1345.

[12] Thambyah A., Nather A., Goh J., Mechanical properties of articular cartilage covered by the meniscus, Osteoarthritis and Cartilage, Vol. 14, No. 6, June, 2006, pp. 580-588.

[13] Trabelsia O., Pérez del Palomara A., López-Villalobos J. L., Ginel A., Doblaré M., Experimental characterization and constitutive modeling of the mechanical behavior of the human trachea, Medical Engineering \& Physics, Vol. 32, No. 1, January, 2010, pp. 76-82.

[14] Buckley M. R., Gleghorn J. P., Bonassar L. J., Cohen I., Mapping the depth dependence of shear properties in articular cartilage, Journal of Biomechanics, Vol. 41, No. 11, August, 2008, pp. 2430-2437.

[15] Haut D. T. L., Hull M. L., Rashid M. M., Jacobs C. R., A finite element model of the human knee joint for the study of tibio-femoral contact, Journal of Biomechanical Engineering, Vol. 124, No. 3, June, 2002, pp. 273-280.

[16] Wei H-W, Sun S-S, Jao S-HE, Yeh C-R, Cheng C-K, The influence of mechanical properties of subchondral plate, femur and neck on dynamic stress distribution of the articular cartilage, Medical Engineering \& Physics, Vol. 27, No. 4, May, 2005, pp. 295-304.

[17] Li G., Park S. E., DeFrate L. E., Schutzer M. E., Ji L., Gill T. J., Rubash H. E., The cartilage thickness distribution in the tibiofemoral joint and its correlation with cartilage-to-cartilage contact, Clinical Biomechanics, Vol. 20, No. 7, August, 2005, pp. 736-744.

[18] Bingham J. T., Papannagari R., Van de Velde S. K., Gross C., Gill T. J., Felson D. T., Rubash H. E., Li G., In vivo cartilage contact deformation in the healthy human tibiofemoral joint, Rheumatology, Vol. 47, No. 11, November, 2008, pp. 1622-1627.

[19] Carballido-Gamio J., Bauer J. S., Stahl R., Lee K. Y., Krause S., Link T. M., Majumdar S., Inter-subject comparison of MRI knee cartilage thickness, Medical Image Analysis, Vol. 12, No. 2, April, 2008, pp. 120-135.

[20] Mow V. C., Gibbs M. C., Lai W. M., Zhu W. B., Athanasiou K. A., Biphasic indentation of articular cartilage-II. A numerical algorithm and an experimental study, Journal of Biomechanics, Vol. 22, No. 8-9, 1989, pp. 853-861.
[21] Mak A. F., Lai W. M., Mow V. C., Biphasic indentation of articular cartilage-I. Theoretical analysis, Journal of Biomechanics, Vol. 20, No. 7, 1987, pp. 703-714.

[22] Loubet J. L., Lucas B. N., Oliver W. C., Some Measurements of viscoelastic properties with the help of nanoindentation, NIST Special publication 896: International Workshop on Instrumented Indentation, 1995, pp 31-34, San Diego, CA, USA, April.

[23] Lyyra T., Kiviranta I., Vaatainen U., Helminen H. J., Jurvelin J. S., In vivo characterization of indentation stiffness of articular cartilage in the normal human knee, Journal of Biomedical Materials Research, Vol. 48, No. 4, 1999, pp. 482-487.

[24] Hayes W. C., Keer L. M., Herrmann G., Mockros L. F., A mathematical analysis for indentation tests of articular cartilage, Journal of Biomechanics, Vol. 5, No. 5, September, 1972, pp. 541-551.

[25] Garcia J. J., Altiero N. J., Haut R. C., An approach for the stress analysis of transversely isotropic biphasic cartilage under impact load, Journal of Biomechanical Engineering, Vol. 120, No. 5, October, 1998, pp. 608-613.

[26] Park S., Hung C. T., Ateshian G. A., Mechanical response of bovine articular cartilage under dynamic unconfined compression loading at physiological stress levels, OsteoArthritis and Cartilage, Vol. 12, No. 1, January, 2004, pp. 65-73.

[27] Park S., Nicoll S. B., Mauck R. L., Ateshian G. A., Cartilage mechanical response under dynamic compression at physiological stress levels following collagenase digestion, Annals of Biomedical Engineering, Vol. 36, No. 3, March, 2008, pp. 425-434.

[28] Huang C. Y., Mow V. C., Ateshian G. A., The role of flow independent viscoelasticity in the biphasic tensile and compressive responses of articular cartilage, Journal of Biomechanical Engineering, Vol. 123, No. 5, October, 2001, pp. 410-417.

[29] Lee R. C., Frank E. H., Grodzinsky A. J., Roylance D. K., Oscillatory compressional behavior of articular cartilage and its associated electromechanical properties, Journal of Biomechanical Engineering, Vol. 103, No. 4, November, 1981, pp. 280-292.

[30] Soltz M. A., Ateshian G. A., Interstitial fluid pressurization during confined compression cyclical loading of articular cartilage, Annals of Biomedical Engineering, Vol. 28, No. 2, February, 2000, pp. 150-159. 
[31] Park S., Hung C. T., Ateshian G. A., Mechanical response of bovine articular cartilage under dynamic unconfined compression loading at physiological stress levels, Osteoarthritis and Cartilage, Vol. 12, No. 1, January, 2004, pp. 65-73.

[32] Barker M. K., Seedhom B. B., Articular cartilage deformation under physiological cyclic loadingApparatus and measurement technique, Journal of Biomechanics, Vol. 30, No. 4, April, 1997, pp. 377-381.

[33] Donzelli P. S., Spilker R. L., Ateshian G. A., Mow V. C., Contact analysis of biphasic transversely isotropic cartilage layers and correlations with tissue failure, Journal of Biomechanics, Vol. 32, No. 10, October, 1999, pp. 1037-1047.

[34] Garcia J. J., Cortes D. H., A nonlinear biphasic viscohyperelastic model for articular cartilage, Journal of Biomechanics, Vol. 39, No. 16, 2006, pp. 2991-2998.

[35] Li L. P., Herzog W., Korhonen R. K., Jurvelin J. S., The role of viscoelasticity of collagen fibers in articular cartilage: axial tension versus compression, Medical Engineering and Physics, Vol. 27, No. 1, January, 2005, pp. 51-57.

[36] Ateshian G. A., Lai W. M., Zhu W. B., Mow V. C., An asymptotic solution for the contact of two biphasic cartilage layers, Journal of Biomechanics, Vol. 27, No. 11, November, 1994, pp. 1347-1360.

[37] Li G., Park S. E., DeFrate L. E., Schutzer M. E., Ji L., Gill T. J., Rubash H. E., The cartilage thickness distribution in the tibiofemoral joint and its correlation with cartilage-to-cartilage contact, Clinical Biomechanics, Vol. 20, No. 7, August, 2005, pp. 736-744.

[38] Mow V. C., Kuei S. C., Lai W. M., Armstrong C. G., Biphasic creep and stress relaxation of articular cartilage in compression- Theory and experiments, J Biomech Eng, Vol. 102, No. 1, February, 1980, pp. 73-84.

[39] Smith P. N., Refshauge K. M., Scarvell J. M., Development of the concepts of knee kinematics, Archives of Physical Medicine Rehabilitation, Vol. 84, No. 12, December, 2003, pp. 1895-1902.

[40] Adam C., Eckstein F., Milz S., Putz R., The distribution of cartilage thickness within the joints of the lower limb of elderly individuals, Journal of Anatomy, Vol. 193, No. 2, August, 1998, pp. 203-214.

[41] Yuehuei H. A., Kylie L. M., Handbook of Histology Methods for Bone and Cartilage, 1st Ed., Humana Press, 2003, pp. 411.
[42] Mankin H. J., Dorfman H., Lippiello L., Zarins A. Biochemical and metabolic abnormalities in articular cartilage from osteoarthritis human hips. II. Correlation of morphology with biochemical and metabolic data, Journal of Bone and Joint Surgery, Vol. 53, No. 3, April, 1971, pp. 523-537.

[43] Franz T., Hasler E. M., Hagg R., Weiler C., Jakob R. P., Mainil-Varlet P., In situ compressive stiffness, biochemical composition, and structural integrity of articular cartilage of the human knee joint, Osteoarthritis and Cartilage, Vol. 9, No. 6, August, 2001, pp. 582-592.

\section{Acknowledgements}

This work was carried out with support from the Instituto Mexicano del Seguro Social (Mexican Social Security Institute), IMSS, the Biomechanics Laboratory of Instituto Tecnologico de Celaya (Technological Institute of Celaya), ITC and the Department of Mechanical Engineering of Universidad de Guanajuato (University of Guanajuato), UG. The authors would also like to thank Dr. Leobardo A. Herrera-May and reviewers for their comments to improve this work. 


\section{Authors' Biographies}

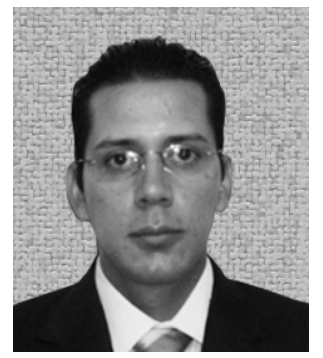

\section{Agustín VIDAL-LESSO}

He obtained a BSc degree in mechanical engineering in 2005 from the University of Guanajuato and an MSc degree in mechanical engineering in 2007 from the Instituto Tecnológico de Celaya (Technological Institute of Celaya). Currently, he is a doctoral candidate and he was awarded as the best student of the doctoral program in 2009 and 2010 by the University of Guanajuato (University of Guanajuato) and he received the State Youth Award 2009 from the State Government of Guanajuato. He has authored/coauthored more than 13 papers in international conference proceedings, a chapter of a book, copyrighted software and unpublished research reports to companies. His current research interests include mechanical behaviour modelling of human tissues, biomechanics and computer aided design.

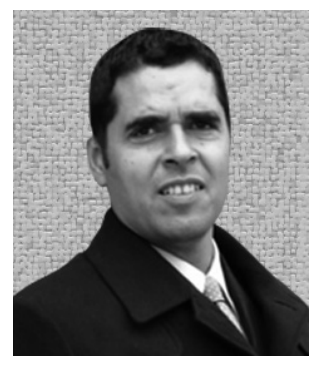

\section{Elías LEDESMA-OROZCO}

Dr. Ledesma obtained an MSc degree (1995) and a Ph.D. degree (2005) in mechanical engineering from the University of Guanajuato. He has a postdoctoral research in the Lawrence Livermore National Laboratory in 2008. $\mathrm{He}$ is currently a full time professor at the Department of Mechanical Engineering of the University of Guanajuato. He is a member of the National System of Researchers in Mexico, SNI. He has patents, papers published in several journals and international conference proceedings. His research fields include mechanical design, hydrogen storage, composite materials, agricultural machinery, FEM, CFD, CAD-CAM, design of experiments and probabilistic design.

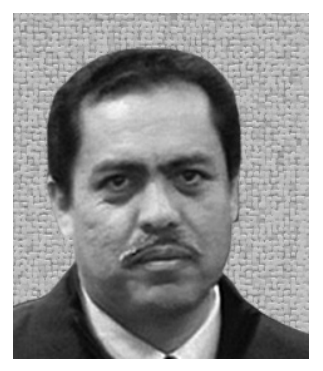

\section{Raúl LESSO-ARROYO}

He received his bachelor's degree in mechanical engineering in 1991, the master's degree in mechanical engineering in 1993, both from the Universidad de Guanajuato, Mexico. For many years, Prof. Lesso worked for different companies and prestigious research institutions in Mexico. In 1994, he joined the Department of Mechanical Engineering of the Instituto Tecnológico de Celaya where, currently, he is a research professor. His main interests include finite element method, biomechanics and computer aided design. Also, he is leader of the area of biomechanics in the Institute. 


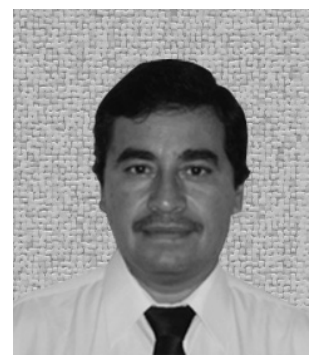

\section{Ramón RODRÍGUEZ-CASTRO}

R. Rodríguez-Castro is native of Celaya, GTO, Mexico. He obtained a BSc degree in mechanical engineering from the Instituto Tecnológico de Celaya, and an MSc degree in applied mechanics from the Instituto Tecnológico de Querétaro. In 1994 he was granted a Fulbright scholarship for doctoral studies in the US. He obtained his $\mathrm{PhD}$ degree in mechanical engineering from the State University of New York at Buffalo in 1999. He has authored/co-authored more than 15 regular papers. His current research interests include mechanical behaviour of materials and numerical simulation. Dr. Rodríguez is currently a full time professor at the Department of Mechanical Engineering of the Instituto Tecnológico de Celaya. 